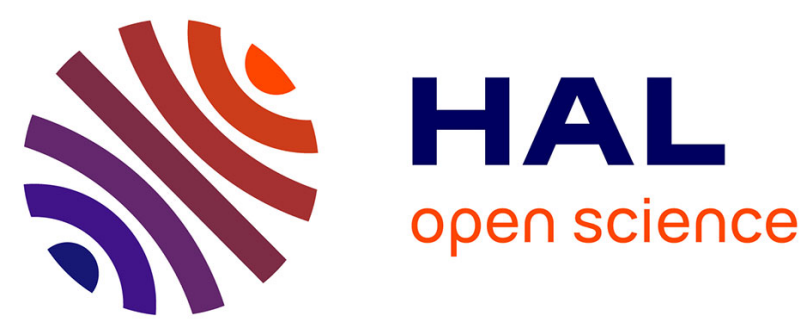

\title{
CD200 is a new prognostic factor in multiple myeloma.
}

Jérôme Moreaux, Dirk Hose, Thierry Rème, Eric Jourdan, Michael Hundemer, Eric Legouffe, Philippe Moine, Philippe Bourin, Marion Moos, Jill Corre, et al.

\section{To cite this version:}

Jérôme Moreaux, Dirk Hose, Thierry Rème, Eric Jourdan, Michael Hundemer, et al.. CD200 is a new prognostic factor in multiple myeloma.. Blood, 2006, 108 (13), pp.4194-7. 10.1182/blood-2006-06029355 . inserm-00130595

\section{HAL Id: inserm-00130595 https://www.hal.inserm.fr/inserm-00130595}

Submitted on 6 Mar 2007

HAL is a multi-disciplinary open access archive for the deposit and dissemination of scientific research documents, whether they are published or not. The documents may come from teaching and research institutions in France or abroad, or from public or private research centers.
L'archive ouverte pluridisciplinaire HAL, est destinée au dépôt et à la diffusion de documents scientifiques de niveau recherche, publiés ou non, émanant des établissements d'enseignement et de recherche français ou étrangers, des laboratoires publics ou privés. 


\section{CD200 is a new prognostic factor in Multiple Myeloma}

Moreaux $\mathrm{J}^{\star \ddagger}$, Hose $\mathrm{D}^{\circ}$, Reme $T^{* \ddagger}$, Jourdan $\mathrm{E}^{\searrow}$, Hundemer $\mathrm{M}^{\circ}$, Legouffe $\mathrm{E}^{\S}$, Moine $\mathrm{P}^{*}$,

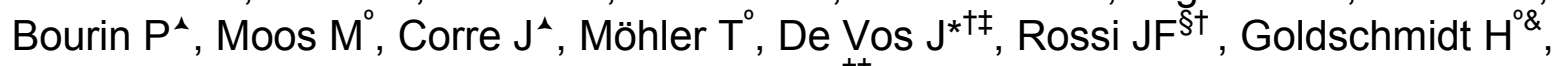
Klein $B^{\star \dagger \ddagger}$

* CHU Montpellier, Institute of Research in Biotherapy, Montpellier, FRANCE;

₹ INSERM, U475, Montpellier, F-34197 France;

${ }^{\circ}$ Medizinische Klinik und Poliklinik V, Universitätsklinikum Heidelberg, Heidelberg, Germany

$\checkmark$ CHU Nimes, Internal Medicine Department B, Nimes, France;

$\S$ CHU Montpellier, Department of Hematology and Clinical Oncology, Montpellier, FRANCE;

^Laboratoire de Thérapie Cellulaire-Etablissement Français du sang, PyrénéesMéditerranée, Toulouse, France;

${ }^{\dagger}$ Université MONTPELLIER1, UFR Médecine, Montpellier, France;

\& Nationales Centrum für Tumorerkrankungen, Heidelberg, Germany

Corresponding author: Bernard KLEIN

INSERM U475

99, rue Puech Villa

34197 MONTPELLIER Cedex 5

FRANCE

Phone: +33467636125

Fax: + 33467041863

e-mail: klein@montp.inserm.fr

Acknowledgements: This work was supported by grants from the Ligue Nationale Contre Le Cancer (équipe labellisée), Paris, France. It is part of a national program called "Carte d'Identité des Tumeurs » program (CIT) or the Tumor Identity Card developed and funded by the Ligue Nationale Contre le Cancer (http://www.liguecancer.net).

Abstract word count: 150 words

Text word count: 1352 words

\section{Author contributions:}

MJ performed the experiments and participated in the writing of the paper.

$\mathrm{HD}, \mathrm{HM}$, and GH collected bone marrow samples and clinical data and participated in the writing of the paper.

RT and DVJ performed the bio-informatic studies and participated in the writing of the paper.

JE, LE, RJF and MT collected bone marrow samples and clinical data.

MP provided with technical assistance.

MM participated in the writing of the paper.

$\mathrm{BP}$ and $\mathrm{CJ}$ collected bone marrow samples.

$\mathrm{KB}$ participated in the design of the research and the writing of the paper. 


\section{Abstract}

Using Affymetrix microarrays, we identified the expression of the CD200 gene in multiple myeloma cells (MMC) of 112 patients with newly-diagnosed multiple myeloma (MM). The CD200 gene was either absent or present (Affymetrix call) in $22 \%$ and $78 \%$ of MMC, respectively. The CD200 gene is not expressed in cells of the patients' bone marrow (BM). CD200 is a membrane glycoprotein that imparts an immunoregulatory signal through CD200R, leading to the suppression of T-cellmediated immune responses. Patients with $C D 200^{\text {absent }}$ MMC have an increased event free survival (24 months) compared to patients with CD200 present $M M C$ (14 months), after high-dose therapy and stem cell transplantation. In a Cox-proportionalhazard model, the absence or presence of CD200 expression in MMC is predictive for EFS for patients independently of ISS stage or B2M serum levels. Thus, CD200 is an independent prognosis factor for patients with MM that could represent a new therapeutic target in MM. 


\section{Introduction}

Multiple myeloma (MM) is a plasma cell neoplasm characterized by the accumulation of malignant plasma cells within the bone marrow (BM). Several autocrine or paracrine factors can promote multiple myeloma cell (MMC) survival and proliferation 1,2. We anticipate that in the future, the inhibition of MMC growth factors may have clinical applications in combination with other drugs ${ }^{3-6}$.

In order to identify new molecules involved in the communication between MMC and the BM environment, we compared gene expression profiles (GEP) of MMC with those of normal plasma cells, normal plasmablasts and normal peripheral blood B cells. We identified that CD200 was expressed in malignant plasma cells in $78 \%$ of newly-diagnosed patients with MM. CD200, formerly known as OX-2, is a highly conserved type I transmembrane glycoprotein that is expressed by thymocytes, activated $\mathrm{T}$ cells, B cells, dendritic cells, endothelial cells and neurons ${ }^{7}$. The expression of the receptor for CD200 (CD200R1) is described as restricted to myeloid-derived antigen presenting cells and certain populations of $\mathrm{T}$ cells ${ }^{8}$. Three other genes, closely related to CD200R1 and termed CD200R2-4 have been identified, but the function of these encoded proteins, in particular their ability to bind CD200, is not fully elucidated ${ }^{9}$. Several studies have shown that CD200 imparts an immunoregulatory signal through CD200R, leading to the suppression of T-cellmediated immune responses. Increased survival of renal allografts following portal vein immunization with alloantigen correlates with an increase in CD200 expression in both hepatic and splenic dendritic cells (DCs) in a murine model ${ }^{10}$. Tolerance in this setting is reversed with a monoclonal antibody to CD200 ${ }^{11}$. CD200-deficient mice have a compromised capacity to down-regulate the activation of antigen presenting cells. This results in chronic central nervous system inflammation, which causes an 
exaggerated inflammatory response to trauma and an increased susceptibility to develop both experimental autoimmune encephalitis and collagen-induced arthritis ${ }^{12}$. More recently, Gorczynski et al. demonstrated that anti-CD200R(2-4) monoclonal antibodies (MoAb) promote the development of DCs and have the capacity to induce regulatory $T$ cells (Treg) and directly augment the production of Treg in the thymus ${ }^{13}$. In this study, we demonstrate that MMC of $78 \%$ of the patients with newly-diagnosed MM express $C D 200$. For patients included in protocols with high dose chemotherapy (HDC) and autologous hematopoietic stem cell transplantation (ASCT), the presence or absence of CD200 expression is a prognostic factor independent of ISS stage or B2M.

\section{Materials and methods}

\section{Cell samples}

XG human myeloma cell lines (HMCL) were obtained as described ${ }^{14-16}$. SKMM, OPM2, LP1 and RPMI8226 HMCL were purchased from ATTC (LGC Promochem, France). MMC were purified from 112 patients with newly-diagnosed MM after written informed consent was given. These 112 patients were treated with HDC and ASCT. Seven of these 112 patients received allogenic bone marrow transplantation after HDC and ASCT and their event free survival was censured at the time of the allograft. In the series, according to the Durie-Salmon classification, 9 patients were of stage IA, 14 of stage IIA, 83 of stage IIIA, and 6 of stage IIIB. According to the International Staging System (ISS) $)^{17}, 44$ patients were of stage I, 53 of stage II, 15 of

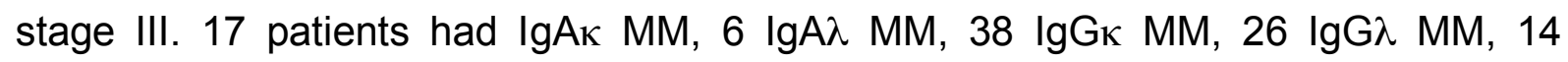
Bence-Jones $\kappa$ MM, 7 Bence-Jones $\lambda$ MM, and 4 non-secreting MM. The obtainment and purification of MMC, normal bone marrow (BM) plasma cells (BMPC), memory B cells, polyclonal plasmablasts, osteoclasts, BM stromal cell lines, BM CD3 T cells, 
BM monocytes and BM polymorphonuclear neutrophils were performed as previously described $^{18}$.

\section{Preparation of complementary RNA (cRNA) and microarray hybridization}

RNA was extracted using the RNeasy Kit (Qiagen, Hilden, Germany). Biotinylated cRNA was amplified with a double in vitro transcription reaction and hybridized to the Affymetrix HG U133 set of Gene Chips, according to the manufacturer's instructions (Affymetrix, Santa Clara, CA).

\section{CD200 expression by MMC}

CD200 expression by primary MMC was determined using a double labeling of primary MMC with a FITC-conjugated anti-CD138 MoAb and a PE-conjugated antiCD200 MoAb (clone MRCOX-104, Becton Dickinson, San Jose, CA), or with FITCor PE- conjugated isotype matched control antibodies. The fluorescence intensity was determined with a FACScan device (Becton Dickinson), setting up the mean fluorescence intensity obtained with the control antibodies between 4 and 6 .

\section{Statistical analysis}

Gene expression data were normalized with the MAS5 algorithm and analyzed with our bioinformatics platforms (RAGE, http://rage.montp.inserm.fr/ and Amazonia, http://amazonia.montp.inserm.fr/). Statistical comparisons were done with $\mathrm{R}$ (http://www.r-project.org/) or SPSS10 (SPSS Chicago, IL) software. 


\section{Results and Discussion}

Comparing the GEP of MMC in an initial series of 48 patients with newly-diagnosed MM with the GEP of normal BM plasma cells, normal plasmablasts and normal memory B cells using Affymetrix U133 A+B DNA-microarrays, we found a clear cut expression of $C D 200$ in MMC. In 9/48 patients, CD200 had an "absent" Affymetrix call $\left(C D 200^{\text {absent }}\right)$ in MMC. In the remaining 39 patients, CD200 had a "present" call $\left(C D 200^{\text {present }}\right)$ in MMC and was overexpressed in MMC compared to normal BMPC (ratio $=6.2$ and $P<.01$ ), plasmablasts (ratio $=26.5$ and $P<.01$ ) or memory B cells (ratio $=10$ and $P<.01)($ Figure $1 \mathrm{~A})$. These data were confirmed with another independent series of MMC from 64 newly-diagnosed patients using Affymetrix U133 2.0 plus microarrays (Figure $1 \mathrm{~A}$ ). Combining the two sets of data, CD200 had a "present" call in MMC in 87 out of $112(78 \%)$ patients. Microarrays CD200 expression was validated by real-time RT-PCR for $20 \mathrm{HMCL}$ and 5 patients' MMC $(r=.81, P<$ .001) (Supplementary data, Figure S1). Using FACS analysis, the CD200 protein was detected on MMC in 13/15 (86\%) consecutive newly-diagnosed patients, confirming the frequency of CD200 expression determined by "absent"/"present" calls with Affymetrix microarrays (Table 1). If CD200 is expressed in MMC, the mean fluorescence intensity ranged from 364 to 8038 (Table 1) (Figure 1B). On the panel of $20 \mathrm{HMCL}$ used, only HMCL with detectable CD200 mRNA displayed a positive labeling with the anti-CD200 MoAb. Moreover, we found a very good correlation ( $r=$ .92; $P<.001$ ) between Affymetrix CD200 expression and protein expression (Mean fluorescence intensity) at the surface of our HMCL (Supplementary data, Figure S2). Subsequently, we investigated the CD200 gene expression in the BM environment from patients with MM. CD200 was not expressed by CD14 monocytes, CD15 polynuclear cells and CD3 T cells that were purified from the BM of 5 newly- 
diagnosed patients. It is also not expressed in 7 osteoclast samples (Figure 1 A). BM stromal cells from 5 patients with MM expressed CD200, but at a 3.9 fold lower median signal compared to that in $C D 200^{\text {present }} \mathrm{MMC}(P=.04) . \mathrm{CD} 34^{+}$hematopoietic stem cells from 5 patients with MM expressed CD200, but at a 2.5 fold lower median signal compared to that in $C D 200^{\text {present }} \mathrm{MMC}(P=.05)$.

A significantly higher number of patients with $C D 200^{\text {present }}$ had a monoclonal protein containing lambda-light chains, whereas an age $\geq 65$ years appeared at a significantly higher frequency in patients with $C D 200^{\text {absent }} \mathrm{MMC}$ (Supplementary data Table A). In our group of 112 newly-diagnosed patients treated with HDT and ASCT, patients with $C D 200^{\text {absent }}$ MMC had a better event free survival (24 months) compared to patients with $C D 200^{\text {present }}$ MMC (14 months) (Figure $1 \mathrm{C}$ ). In a Coxproportional-hazard model monitoring for the absence or presence of $C D 200(P=$ $0.04)$ and ISS-stage $(P=0.01)$, both parameters are independently predictive for EFS $(P=0.01)$. If $C D 200$ expression is tested together with classical prognostic factors, i.e. serum albumin and serum $\beta 2 \mathrm{M}, \mathrm{CD} 200$ expression $(P=0.04)$ and B2M $(P=0.015)$ remain independent prognostic factors, whereas serum albumin marginally fails to be significant $(P=0.058)$.

This better EFS of patients with MMC lacking CD200 could be linked to the role of CD200 in suppression of T-cell-mediated immune responses and in the development of DC with a capacity to induce $\operatorname{Treg}^{9-11,13}$. A recent study has demonstrated that B cell chronic lymphocytic leukemia expresses CD200 that leads to inhibition of the Th1 response in mixed lymphocyte reactions ${ }^{19}$. In conclusion, we have identified that CD200 expression by MMC is an independent prognostic factor for patients with MM that could represent a new therapeutic target. 


\begin{tabular}{|c|c|c|}
\hline & \multicolumn{2}{|c|}{ CD200 labeling } \\
\hline Patient & \% & MFI \\
\hline 1 & 84.8 & 2273 \\
\hline 2 & 90.4 & 4347 \\
\hline 3 & 88.8 & 986 \\
\hline 4 & 97.7 & 2023 \\
\hline 5 & 80 & 1219 \\
\hline 6 & 98.1 & 1155 \\
\hline 7 & $<5$ & - \\
\hline 8 & 99.6 & 8038 \\
\hline 9 & $<5$ & - \\
\hline 10 & 95.9 & 804 \\
\hline 11 & 95.6 & 832 \\
\hline 12 & 30.7 & 364 \\
\hline 13 & 99.9 & 1259 \\
\hline 14 & 62 & 601 \\
\hline 15 & 97.8 & 442 \\
\hline
\end{tabular}

Table 1: CD200 expression at the surface of myeloma cells.

CD200 expression by primary MMC was determined using a double labeling of primary MMC with a FITC-conjugated anti-CD138 MoAb and a PE-conjugated antiCD200 MoAb, or with FITC- or PE-conjugated isotype matched control antibodies. The fluorescence intensity was determined with a FACScan device, setting up the mean fluorescence intensity obtained with the control antibodies between 4 and 6 . 


\section{Figure legends}

Figure 1. CD200 expression and association with event free survival in patients with MM.

(A) Affymetrix CD200 gene expression in normal memory B cells, normal polyclonal plasmablasts, normal BM plasma cells (BMPC), purified myeloma cells from patients with multiple myeloma (MM), human myeloma cell lines, BM stromal cells, BM CD34 cells, purified BM CD15, CD14 and CD3 cells and osteoclasts.

(B) CD200 expression by primary MMC or normal BMPC was determined using a double labeling of primary MMC with a FITC-conjugated anti-CD138 MoAb and a PEconjugated anti-CD200 MoAb, or with FITC- or PE- conjugated isotype matched control antibodies.

(C) Kaplan-Meier plot of the event free survival in patients with $C D 200^{\text {present }}$ and $C D 200^{\text {absent }} M M C$.

\section{$\underline{\text { References }}$}

1. Klein B, Tarte K, Jourdan M, et al. Survival and proliferation factors of normal and malignant plasma cells. Int J Hematol. 2003;78:106-113.

2. De Vos J, Hose D, Reme T, et al. Microarray-based understanding of normal and malignant plasma cells. Immunol Rev. 2006;210:86-104.

3. Klein B, Wijdenes J, Zhang XG, et al. Murine anti-interleukin-6 monoclonal antibody therapy for a patient with plasma cell leukemia. Blood. 1991;78:1198-1204.

4. Bataille R, Barlogie B, Lu ZY, et al. Biologic effects of anti-interleukin-6 murine monoclonal antibody in advanced multiple myeloma. Blood. 1995;86:685-691.

5. Rossi JF, Fegueux N, Lu ZY, et al. Optimizing the use of anti-interleukin-6 monoclonal antibody with dexamethasone and $140 \mathrm{mg} / \mathrm{m} 2$ of melphalan in multiple myeloma: results of a pilot study including biological aspects. Bone Marrow Transplant. 2005;36:771-779.

6. Rossi JF, Moreaux J, Requirand G, Bouseida S, Picard M, Ythier A, Sievers E, Klein B. A phase I/II study of TACI-Ig to neutralize APRIL and BLyS in patients with refractory or relapsed multiple myeloma or active previously-treated waldenström's macroglobulinemia. Blood. 2005;106.

7. Barclay AN, Wright GJ, Brooke G, Brown MH. CD200 and membrane protein interactions in the control of myeloid cells. Trends Immunol. 2002;23:285-290. 
8. Wright GJ, Cherwinski H, Foster-Cuevas M, et al. Characterization of the CD200 receptor family in mice and humans and their interactions with CD200. J Immunol. 2003; 171:3034-3046.

9. Gorczynski RM. CD200 and its receptors as targets for immunoregulation. Curr Opin Investig Drugs. 2005;6:483-488.

10. Gorczynski RM, Chen Z, Fu XM, Zeng H. Increased expression of the novel molecule OX-2 is involved in prolongation of murine renal allograft survival. Transplantation. 1998;65:1106-1114.

11. Gorczynski RM, Cohen Z, Fu XM, Lei J. Anti-rat OX-2 blocks increased small intestinal transplant survival after portal vein immunization. Transplant Proc. 1999;31:577578.

12. Hoek RM, Ruuls SR, Murphy CA, et al. Down-regulation of the macrophage lineage through interaction with OX2 (CD200). Science. 2000;290:1768-1771.

13. Gorczynski RM, Lee L, Boudakov I. Augmented Induction of CD4+CD25+ Treg using monoclonal antibodies to CD200R. Transplantation. 2005;79:1180-1183.

14. Zhang XG, Gaillard JP, Robillard N, et al. Reproducible obtaining of human myeloma cell lines as a model for tumor stem cell study in human multiple myeloma. Blood.

1994;83:3654-3663.

15. Rebouissou C, Wijdenes J, Autissier P, et al. A gp130 interleukin-6 transducerdependent SCID model of human multiple myeloma. Blood. 1998;91:4727-4737.

16. Gu ZJ, Vos JD, Rebouissou C, et al. Agonist anti-gp130 transducer monoclonal antibodies are human myeloma cell survival and growth factors. Leukemia. 2000;14:188-197. 17. Greipp PR SMJ, Fonseca R, Avet-Loiseau H, Jacobson JL, Rasmussen E, Crowley J, Durie BMG. Development of an international prognostic index (IPI) for myeloma: report of the international myeloma working group. Hematology Journal. 2003;4.

18. Moreaux J, Cremer FW, Reme T, et al. The level of TACI gene expression in myeloma cells is associated with a signature of microenvironment dependence versus a plasmablastic signature. Blood. 2005;106:1021-1030.

19. McWhirter JR, Kretz-Rommel A, Saven A, et al. Antibodies selected from combinatorial libraries block a tumor antigen that plays a key role in immunomodulation. Proc Natl Acad Sci U S A. 2006;103:1041-1046. 

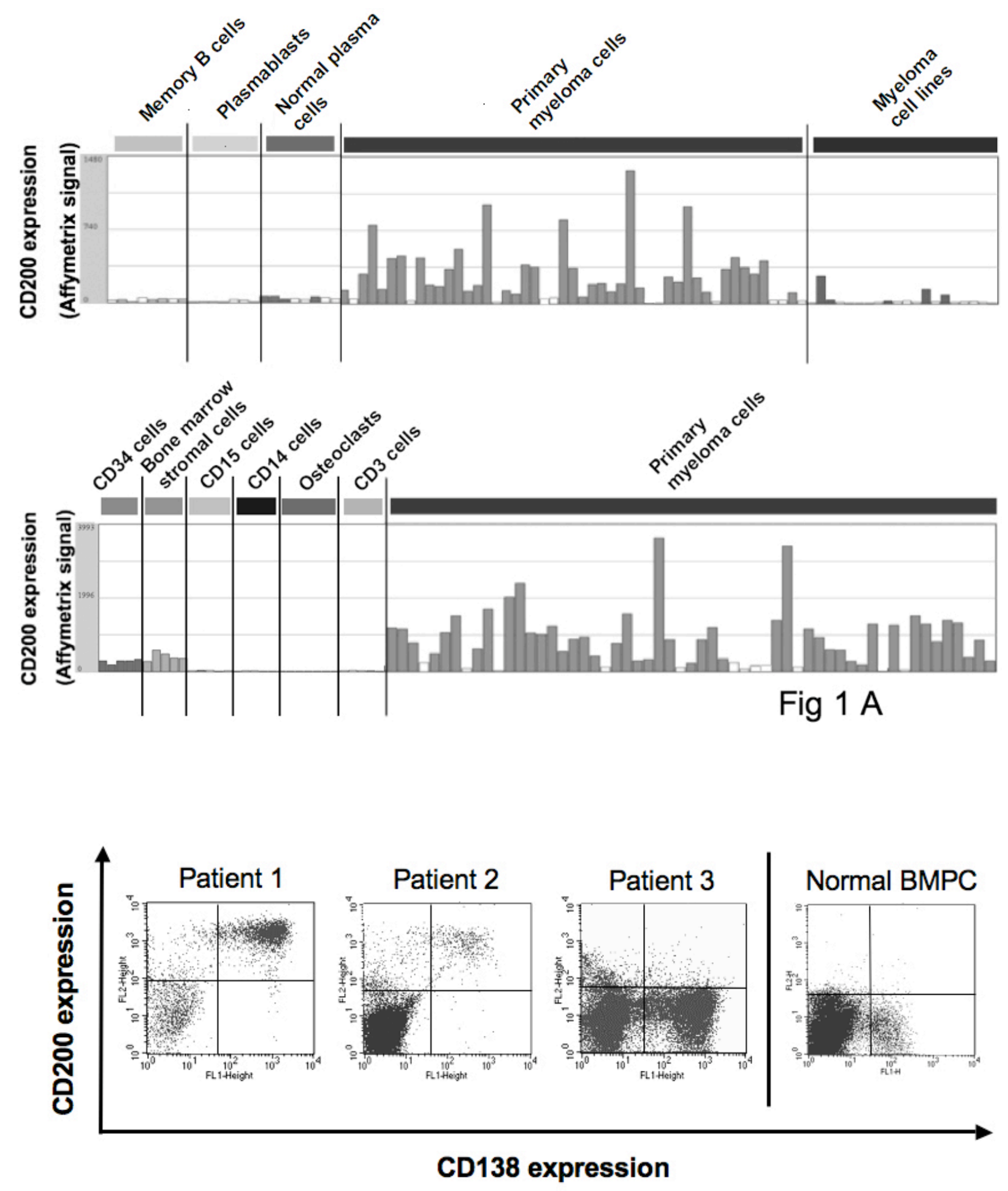

Fig 1 B 


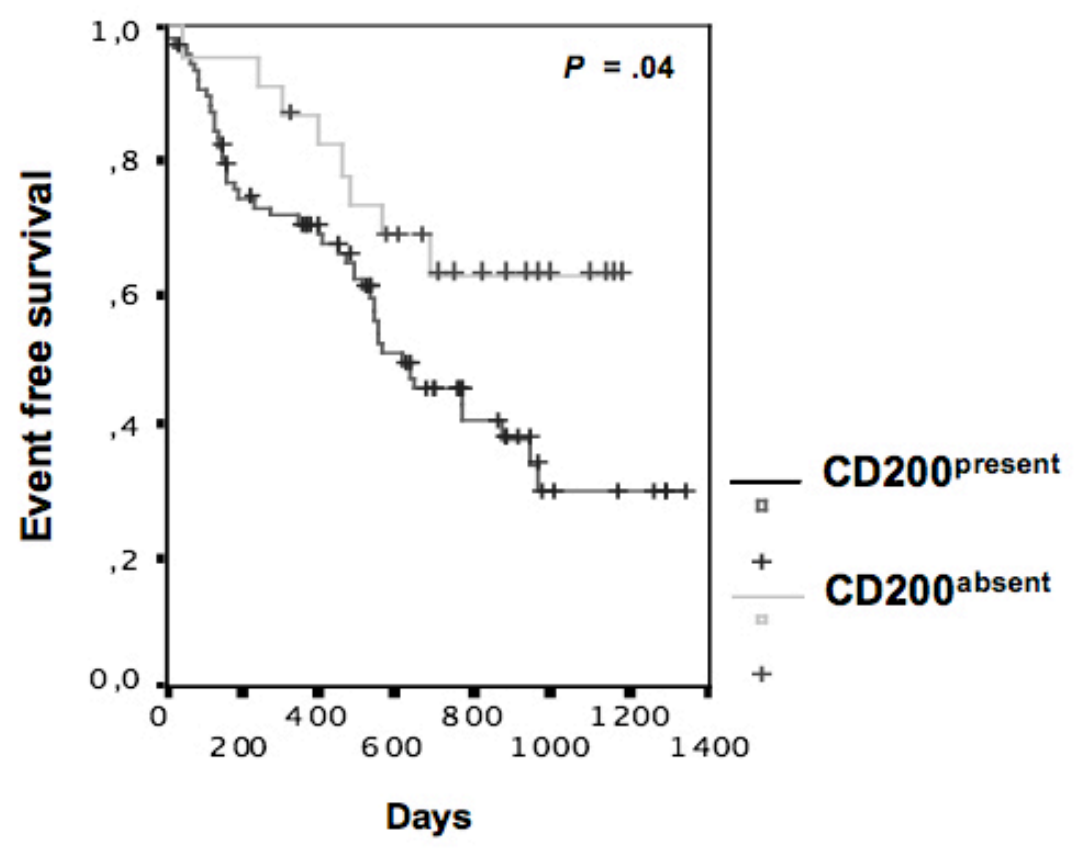

Fig $1 \mathrm{C}$ 